\title{
EPIDEMIOLOGICAL ASPECTS OF SYSTEMIC LUPUS ERYTHEMATOSUS' PATIENTS IN THE STATE OF RORAIMA: A PRELIMINARY STUDY
}

\author{
Narottam Sócrates Garcia Chumpitaz ${ }^{1, *}$, Rodrigo dos Santos da Silva ${ }^{1}$, Kamila Kendra Mar Marques ${ }^{1}$, Pâmella Graziella Gomes \\ Fontenelle ${ }^{1}$, Jhon Andreo Almeida dos Santos ${ }^{1}$, Paula Vitória de Oliveira Sales ${ }^{1}$, Rafael Veras Rodrigues ${ }^{1}$, Guilherme Henrique \\ Barros Borges ${ }^{1}$, Victhoria Castilho Simão ${ }^{1}$, Pedro Gabriel de Carvalho Alkas ${ }^{1}$, Bruno Leitão da Silva²
}

1.Universidade Federal de Roraima, Boa Vista (RR), Brazil; 2.Clínica Médica Especializada Coronel Mota, Boa Vista (RR), Brazil.

*Corresponding author: narottamgarcia@gmail.com

\section{BACKGROUND}

Systemic lupus erythematosus (SLE) is a chronic inflammatory disease which cause is still not very well established in the literature, but its natural autoimmunity reaches multiple systems in the human body. This disease is prevalent in people of any age, race and sex, but women are substantially more affected, according to the Brazilian Society of Rheumatology. In the state of Roraima, there are still no studies in the academic-scientific database that investigate the epidemiological aspects of SLE. This lack of data contributes to the lack of information at regional and national levels.

\section{METHODS}

This is an observational nature study, cross-sectional and prospective/retrospective, quantitative/descriptive approach, based on documentary and field research, with analysis of patients residing in Roraima, SLE diagnosis, aged between 14 and 70 years old, and monitored at the only referral service in rheumatology at the secondary hospital in Boa Vista, the state capital. The survey was first approved by the Ethics and Research Committee in September 2020. All immigrant patients who did not speak Portuguese or Spanish, indigenous patients regardless of ethnicity, and those outside the specified age group were excluded from the analysis.

\section{RESULTS}

The study sample consisted of 44 patients with SLE, evaluated between November 2020 and July 2021. The majority profession was housewife (45.45\%), followed by public servant (11.36\%), student $(9.09 \%)$ and, with the same numbers, self-employed, teacher and others (6.81\%). Most declared themselves as brown (pardos) ( $72.72 \%$ ), and the predominant religion was Christianity (68.18\%). It was shown that $90.9 \%$ of the patients are residents of the capital Boa Vista, and $26.5 \%$ live in rural areas across the state. The prevalence of school level was complete high school (59.1\%). In terms of family income, the predominance (50\%) is between 1 and 3 minimum wages.

\section{CONCLUSION}

The results show the prevalence of females, as expected in the literature, Christians, housewives, browns, coming from the state capital, with high school education. As for family income, the average salary was between 1 and 3 Brazilian minimum wages and the average age was 37 years old. Besides that, the clinical aspects such as frequency of complications and morbidity were similar to those already established by references.

\section{KEYWORDS}

Systemic lupus erythematosus, Epidemiology, Roraima. 